власти должны осуществлять поиск решений проблем, включая, например, обеспечение благоприятных внешних условий для эффективного использования денежных средств, их оборачиваемости, объема денежной массы. Региональная финансовая система выступает как система управления денежными средствами целой цепочки взаимосвязанных хозяйствующих субъектов и оборотом денежных средств населения региона. Здесь свою регулирующую роль должны играть региональные и местные органы власти. В частности это - поддержание интеграции хозяйственных интересов по «щепочкам приращения стоимости» регионально значимых продуктовых направлений с целью максимальной эффективности производства такой продукции. Еще одним важным моментом является создание положительной репутации в обществе от улучшения внешней среды и качества жизни населения.

В случае если основной спектр задач по управлению денежным обращением будет переложен на региональные органы власти, то это может обеспечить высокую вероятность того, что поддержка региональных предпринимателей, находящихся в кризисном положении, будет осуществляться более оптимально и обоснованно. Ввиду этого эффект от привлечения денежных средств региона будет кумулятивным за счет отсутствия ситуации, когда денежные средства будут задерживаться во владении посредников, не занимающихся напрямую производственной деятельностью. Это позволит в конечном итоге обеспечить развитие всего региона в целом и в конечном итоге улучшит положение самого населения.

$$
* * *
$$

1. Галанов В.А. Финансы, денежное обращение и кредит: учебник / В.А. Галанов. -2 -е изд. - М.: ИНФРА-М, 2017. - $414 \mathrm{c.}$

2. Гояев А.М. Современная проблематика инструментов привлечения денежных средств населения во вклады коммерческих банков // Научная дискуссия: инновации в современном мире. - 2017. - № 11. - C. $41-46$

3. Колпакова Г.М. Финансы, денежное обращение и кредит: учебник / Г.М. Колпакова, Ю.В. Евдокимова. - 5-е изд., перераб. и доп. - М.: ИНФРА-М, 2019. - 609 с.

4. Сафиуллин А.Р. Формирование благосостояния населения: современные тенденции и Россия: Монография / А.Р. Сафиуллин - М.: ИЦ РИОР, НИЦ ИНФРА-М, 2019. - 215 с.

5. Стародубцева Е.Б. Основы банковского дела: учебник / Е.Б. Стародубцева. - 2-е изд., перераб. и доп. - М.: ИД «ФОРУМ» : ИНФРА-М, 2018. — 288 c.

\title{
Килина А.А. \\ Современное состояние системы привлечения денежных средств населения на российском рынке
}

doi: $10.18411 / \mathrm{lj}-02-2021-84$

idsp: ljournal-02-2021-84

\section{Аннотация}

На сегодняшний момент у России имеется достаточно четко сформированная финансовая система. В тоже время сохраняется проблема трансформации денежных средств в инвестиционные проекты и их своевременное привлечение в развитие экономики РФ. Ввиду этого, в статье рассмотрено современное состояние системы привлечения денежных средств населения, а также дана оценка ее возможности дальнейшего развития.

Ключевые слова: денежные средства, Центральный банк, коммерческие банки, население, банковская система.

\section{Abstract}

Today, Russia has a fairly well-formed financial system. At the same time, the problem of transforming funds into investment projects and their timely involvement in the development of the Russian economy remains. In view of this, the article examines the 
current state of the system for attracting funds from the population, as well as an assessment of the possibilities for further development.

Keywords: cash, Central Bank, commercial banks, population, banking system.

Многие коммерческие банки в России некоторое время назад концентрировали свою деятельность на основе привлечения денежных средств в первую очередь коммерческих организаций. Это характеризовалось тем, что за обслуживание платежеспособных, финансово-устойчивых организаций, имеющих значительные денежные обороты, шла серьезная конкурентная борьба. В тоже время сбережениям населения уделялось несколько меньшее внимание. В настоящее время данная ситуация значительно меняется, что предопределяется в первую очередь рыночной конъюнктурой российской экономики. Актуальность роста внимания к привлечению денежных средств населения, в частности, выросла ввиду необходимости повышения инвестиционных ресурсов на рынке, снижение темпов роста инфляции, важность пополнения банковского капитала, обеспечение роста уровня жизни населения.

Важно отметить, что на сегодняшний день депозитный рынок в сфере банковских услуг является одним из самых развивающихся направлений и в первую очередь это связано с развитием рынка вкладов в первую очередь населения. При помощи активной работы коммерческих банков, денежно-кредитная система России имеет возможность оптимально аккумулировать сбережения населения и перераспределять их, используя их в качестве инвестиционных ресурсов. Важно отметить, что вклады для населения являются одним из самых распространенных видов инвестиций, хотя зачастую и он не превышает по доходности даже уровня инфляции. Согласно макроэкономической статистике, в последние пять лет заметно значительное увеличение объемов вкладов населения в коммерческих банках, в частности, долгосрочных вкладов.

Данная ситуация является позитивной для денежно-кредитной системы страны, поскольку привлечение средств населения является одним из наиболее значимых и существенных механизмов обеспечения оборачиваемости выпущенных в обращение наличных денежных средств. В соответствии с этим, стимулирование банками деятельности по привлечению сбережений населения можно определить как наиболее приоритетную в области развития денежно-российской денежно-кредитной системы.

При этом необходимо отметить, что с учетом основной цели коммерческого банка - получение прибыли, последним выгодно большую долю иметь срочных вкладов, а также вкладов до востребования, ввиду того, что такие вклады являются наиболее дешевой ресурсной базой. Процент по таким вкладам, как правило, низкий, либо вообще отсутствует. Несмотря на то, что данные средства в любой момент времени могут быть изъяты со счетов, у банков имеются в любой момент времени необходимый объем ресурсов для выдачи данных средств (при условии обеспечения нормальной платежеспособности). Статистику в разрезе структуры депозитов населения в российских банках отразим в таблице 1.

Таблица 1

Анализ динамики и структуры средств населения в банках, млрд. руб. [5]

\begin{tabular}{|c|c|c|c|c|c|c|}
\hline Показатель & 2013 & 2014 & 2015 & 2016 & 2017 & 2018 \\
\hline $\begin{array}{c}\text { Средства } \\
\text { клиентов, всего }\end{array}$ & 19729592 & 23171691 & 26455846 & 27523647 & 31286296 & 33952306 \\
\hline $\begin{array}{c}\text { В том числе до } \\
\text { востребования }\end{array}$ & 6632980 & 7055140 & 8232141 & 7983793 & 9207010 & 9289151 \\
\hline Доля & 36,65 & 30,45 & 31,12 & 29,00 & 29,43 & 27,36 \\
\hline
\end{tabular}

Важно отметить, что в последние годы доля вкладов до востребования как наиболее выгодных для банков снижается. Это в свою очередь обуславливает 
необходимость развития депозитной политики со стороны банков, а также инструментов по привлечению денежных средств.

Увеличение значимости процесса привлечения денежных средств населения банками обуславливается также трудностями, которые в последние годы испытывала банковская отрасль. В частности, по различным причинам, в том числе и ввиду отсутствия достаточной доли капитала, отсутствия платежеспособности, ликвидности, число действующих коммерческих банков в России снижается. Например, за 2018 год данное число сократилось на 62 финансовых учреждения. Центральный банк РФ при этом только ужесточает требования, которым должны соответствовать коммерческие банки. В таблице 2 представим динамику действующих банков в России за 2010-2018гг.

Таблийа 2

Динамика действующих банков в России за 2010-2018г2. [5]

\begin{tabular}{|c|c|c|c|c|c|c|c|c|c|}
\hline Показатель & 2010 & 2011 & 2012 & 2013 & 2014 & 2015 & 2016 & 2017 & 2018 \\
\hline $\begin{array}{c}\text { Число } \\
\text { банков }\end{array}$ & 1058 & 1012 & 978 & 956 & 923 & 834 & 733 & 623 & 561 \\
\hline
\end{tabular}

Наличие проблем у бизнес-сообщества, усиление влияния зарубежных санкций, иных внешних факторов снижает эффективность осуществления предпринимательской деятельности в стране. Согласно статистическим данным, на конец 2019 года кредитный портфель банков в малом и среднем бизнесе снизился на $20 \%$ от уровней конца 2018 года, а доля просроченной задолженность достигла 15-20\%. Это напрямую влияет на состояние инвестиционного климата страны, возможностей ее развития. При этом возместить риски непогашения выданных кредитов, повышая ставки кредитов банки не могут, поскольку они и так по некоторым оценкам являются завышенными для населения и предпринимателей, что будет только снижать их прирост деятельности.

Ввиду этого депозитные операции банков являются наиболее важным ресурсом для банка, который может компенсировать потенциальные потери от кредитования, обеспечить стабильную величину капитала и платежеспособность.

Отдельного внимания актуальность привлечения денежных средств населения также обуславливается такими факторами, как: законодательство, состояние и развитие финансового рынка, макроэкономические показатели (среди которых основным является ключевая ставка). В рамках особенностей финансового рынка необходимо выделить следующие аспекты: недостаток реальных экономических и политических предпосылок для стабилизации и оживления экономики, увеличение инфляционных ожиданий, снижение реальных доходов населения, непрогнозируемая девальвация, упадок доверия к экономическим институтам. Учитывая выделенные нами аспекты, можно сделать вывод, что ими обуславливается сокращение числа банковских учреждений, что в свою очередь привело к ограничению некоторых возможностей по удовлетворению потребностей реального сектора экономики в заимствованиях за счет внутренних ресурсов.

В рамках развития привлечения денежных средств населения должны в обязательном порядке учитываться непосредственно интересы самого населения не только в разрезе совершенствования их социального уровня, но также и по качеству предоставления финансовых услуг по хранению и преумножению денежных средств. В данной части коммерческие банки должны учитывать то, что на практике различаются различные группы и виды населения, которые имеют различный социальный уровень и возможности по размещению вкладов. В свою очередь, основной целью депозитной политики коммерческих банков должно быть также привлечение оптимального объема денежных ресурсов населения, который был бы достаточен для успешного функционирования российской экономики, финансовых и производственных рынков в частности с учетом нормального уровня издержек. В данной части выделяются, как 
правило, следующие варианты инструментов для достижения целей депозитной политики банка [1, с. 42]:

1) открытие и ведение счетов юридических и физических лиц, предполагающее поступление на эти счета денежных средств;

2) открытие и ведение счетов других банков, предполагающее поступление на эти счета денежных средств;

3) выпуск и продажа банковских векселей;

4) открытие на банк лимитов со стороны других банков, позволяющее привлекать ресурсы в форме межбанковских кредитов.

В рамках привлечения банками сбережений населения важно отметить, что значительный объем внимания для обеспечения конкурентоспособности уделяется в первую очередь скорости и простоте оформления вкладов, это позволяет банкам становится более клиентоориентированными. Это особенно актуально в условиях снижающегося числа банковских учреждений.

При этом на результативность обеспечения денежно-кредитной системы также влияет и уровень доходов населения, который является по сути одним из наиболее важных показателей социально-экономического положения страны. Важно отметить, что чем более высоким является уровень экономического развития в стране, тем выше будут значения номинальных и реальных доходов граждан, которые необходимо перераспределять внутри денежно-кредитной системы. И с ростом доходов населения данный процесс перераспределения будет осуществляться более оптимально. Современные статистические данные о динамике доходов населения свидетельствуют о некотором росте номинальных доходов при одновременном отсутствии положительных результатов динамики индекса реальных доходов населения за 20152018гг. Представим их в таблице 3.

Таблица 3

Среднемесячная начисленная заработная плата работников в РФ за 2014-2018г2. [4]

\begin{tabular}{|l|c|c|c|c|c|c|}
\hline \multicolumn{3}{|c|}{ Показатель } & 2014 & 2015 & 2016 & 2017 \\
\hline $\begin{array}{l}\text { Номинальная среднемесячная заработная } \\
\text { плата, руб. }\end{array}$ & 32495 & 34030 & 36746 & 39482 & 42307 \\
\hline $\begin{array}{l}\text { Темп роста реальной } \\
\text { зарплаты (индекс, \%) }\end{array}$ & среднемесячной & 101,2 & 91,0 & 100,7 & 102,7 & 101,9 \\
\hline
\end{tabular}

Можно сделать вывод, что текущая динамика реальной и номинальной заработной платы населения изменяется под влиянием в первую очередь кризисных явлений, как в российской, так и мировой экономик. Это также влияет на склонность к сбережению среди населения и формирует проблемы по привлечению денежных средств населения в денежно-кредитную систему России.

Кроме указанных выше проблем, требующих выработки определенных решений, также можно отдельно выделить проблему инфляции. Предполагалось, что сокращение инфляционных процессов позволит создать основу, которая сможет способствовать росту экономического положения России, а также обеспечит инвестиционную привлекательность экономики. Но фактически, меры, при помощи которых государство достигло снижения инфляции, носили, по своей сути, разнонаправленный характер. В рамках финансовой и денежно-кредитной политики это выражалось в снижении расходов бюджета, а также политики Центрального банка РФ по повышению ключевой ставки. В конечном итоге данные меры не позволили обеспечить должный рост реальных доходов населения и фактически ограничили платежеспособный спрос, что еще в большей мере актуализировало процесс привлечения денежных средств населения.

Текущая ситуация, характеризующаяся низкими темпами роста реальной заработной платы, влияет негативно на темпы увеличения ВВП, что выражается 
фактически тем, что при отсутствии роста реальной заработной платы снижается емкость внутреннего рынка. Чем меньше спрос на рынке, тем меньшим будет объем производства. Кроме того низкий платежеспособный спрос не благоприятствует также развитию инвестиционного потенциала страны.

В целях потенциального устранения указанных выше проблем в рамках привлечения денежных средств населения, на наш взгляд, необходимо в первую очередь обеспечить приемлемую доходность в рамках накопления денежных средств в банковской системе при условии одновременной минимизации рисков утери средств. Последнее также остается проблемой, особенно в условиях сокращения числа банков. При ликвидации коммерческого банка вклады населения хоть и застрахованы государством, но сумма страхования составляет лишь 1400000 руб. по одному вкладу. То есть при накоплении на счете сверх указанной суммы, при наступлении страхового случая население получит средства не выше указанной суммы.

По нашему мнению необходимо продолжить развитие системы страхования вкладов, а также усилить интеграционные процессы по участию банка в качестве посредника на финансовом рынке, а также более оптимальному контролю деятельности банков для предупреждения возникновения их неплатежеспособности.

Текущее исследование актуальности привлечения денежных средств населения, в конечном итоге, характеризуется следующими аспектами:

1) сокращение объемов вкладов в условиях низкого уровня роста реальных доходов населения, что соответственно выражается в низкой покупательной способности населения и недостаточном получении доходов для покрытия текущих потребностей;

2) увеличение объемов вкладов населения позволяет сделать вывод, что население в ущерб текущему потреблению формирует собственные сбережения. Это в первую очередь подтверждает негативный прогноз со стороны населения, как собственного благосостояния, так и перспектив развития страны.

На основе вышеприведенного можно сделать вывод, что значимость привлечения денежных средств населения является важной для денежно-кредитной системы, а также экономики в целом. Важная роль в данной части лежит на системе страхования вкладов населения, а также депозитной политике коммерческих банков. Но учитывая значимость совершенствования данного механизма важным является обеспечение развития банковской системы в целом, поскольку текущая динамика их совершенствования носит несколько неоптимальный характер. Число банковских учреждений сокращается, Центральным банком ужесточаются правила ведения деятельности при одновременном ухудшении макроэкономических показателей. Тем самым является актуальной выработка более оперативных и точных методов привлечения денежных средств населения, которые позволят повысить результативность российской экономики в целом и увеличить благосостояние населения.

$$
* * *
$$

1. Гояев А.М. Современная проблематика инструментов привлечения денежных средств населения во вклады коммерческих банков // Научная дискуссия: инновации в современном мире. - 2017. - № 11. - C. $41-46$

2. Сафиуллин А.Р. Формирование благосостояния населения: современные тенденции и Россия: Монография / А.Р. Сафиуллин - М.: ИЦ РИОР, НИЦ ИНФРА-М, 2019. - 215 с.

3. Стародубцева Е.Б. Основы банковского дела: учебник / Е.Б. Стародубцева. - 2-е изд., перераб. и доп. - М.: ИД «ФОРУМ» : ИНФРА-М, 2018. - $288 \mathrm{c}$.

4. Россия в цифрах. 2018. По материалам Росстата РФ, 2018. URL: https://www.gks.ru/free_doc/doc_2018/rusfig/rus18.pdf/ (дата обращения: 06.03.2020)

5. Количество банков в России - динамика за 2007-2018 годы, уставной капитал и количество банков в разрезе регионов URL: https://bankirsha.com/kolichestvo-bankov-v-rossii-na-konec-goda-finansovyikrizis-ustavnoi-kapital-i-chislennost-bankov.html / (дата обращения: 06.03.2020) 